\title{
AVALIAÇÃO BIOQUÍMICA E HEMOGASOMÉTRICA DE BOLSAS DE SANGUE (CPDA-1) CANINAS MANTIDAS SOB REFRIGERAÇÃO
}

\author{
Cecília Braga Laposy ${ }^{1}$, Rosa Maria Barilli Nogueira ${ }^{1}$ \\ ${ }^{1}$ Docente do Curso de Medicina Veterinária e do Programa de Mestrado em Ciência Animal da UNOESTE
}

\section{RESUMO}

O objetivo do estudo foi avaliar as alterações bioquímicas e hemogasométricas resultantes do armazenamento de bolsas de sangue caninas. Amostras de sangue $(420 \mathrm{~mL})$ foram colhidas de oito cães adultos e hígidos provenientes do canil da Unoeste. Após a coleta, o sangue foi acondicionado em bolsas plásticas com anticoagulante CPDA-1 e armazenadas sob refrigeração (entre -2 e $8^{\circ} \mathrm{C}$ ). Uma alíquota foi retirada imediatamente após a coleta (D0), aos sete (D7), 14 (D14), 21 (D21) e 30 (D30) dias subsequentes, para dosagem da glicose plasmática, sódio, potássio, proteína plasmática total, além da mensuração da $\mathrm{pO}_{2}, \mathrm{pCO}_{2}$, bicarbonato e $\mathrm{pH}$ sanguíneos, por hemogasometria. Houve uma diminuição significativa dos valores de glicose, bicarbonato e pH sanguíneo após 15 dias da coleta. Já o potássio, a proteína plasmática e a $\mathrm{pCO}_{2}$ diminuíram com o decorrer do tempo. Com base nos resultados obtidos, pode-se concluir que as bolsas de sangue, quando armazenadas sob refrigeração, devem ser utilizadas no período máximo de quinze dias, para preservação de seus constituintes.

Palavras-chave: cão; hemogasometria; transfusão de sangue.

\section{BIOCHEMISTRY AND BLOOD GAS EVALUATION OF CANINE BLOOD BAGS WITH CPDA-1 KEPT UNDER REFRIGERATION}

\begin{abstract}
The aim of this study was to evaluate the biochemical and the blood gas following the refrigerated storage of blood bags. Blood samples $(420 \mathrm{~mL})$ of eight healthy dogs were collected and the bags were kept under refrigeration $\left(-2\right.$ to $\left.8^{0} \mathrm{C}\right)$. An aliquot of blood was withdrawn immediately after collection (D0) and on days 7 , 14, 21 and 30 for measurement of plasma glucose, sodium, potassium, total plasma protein and measurement of $\mathrm{pO} 2, \mathrm{pCO} 2$, bicarbonate and blood $\mathrm{pH}$ by blood gas. There was a significant increase of glucose level, bicarbonate and blood $\mathrm{pH}$ after 15 days of collection. On the other hand, potassium, $\mathrm{pCO}_{2}$ and plasma protein decreased with time. In conclusion, the maximum period of 15 days should be adopted for refrigeration of dog blood bags, in order to preserve the blood biochemical and gas characteristics.
\end{abstract}

Keywords: blood gas; blood transfusion; dog. 


\section{INTRODUÇÃO}

A transfusão sanguínea é considerada como uma forma de terapia emergencial frente à perda de sangue, sendo indicada para o tratamento de anemias severas além da reposição dos fatores de coagulação (NUSBACHER, 1994; KRISTENSEN; FELDMAN, 1997; ROZANSKI; LAFORCADE, 2004). É indicada quando da necessidade do restabelecimento da capacidade de transporte de oxigênio pelo sangue, nos casos de deficiência na hemostasia, para transferência de imunidade passiva, e ainda, em casos de hipoproteinemia ou hipovolemia (HOSGOOD, 1990).

A estocagem sanguínea para transfusão é praticada em medicina humana desde que a primeira solução preservativa, o citrato ácido dextrose (ACD), foi desenvolvida em 1943. Subsequentemente, muitos trabalhos têm sido desenvolvidos na tentativa de melhorar a viabilidade e a capacidade funcional do sangue estocado por longos períodos (AUTHEMENT et al., 1986).

A viabilidade do sangue estocado está na dependência da técnica utilizada na coleta do material, tipo de anticoagulante utilizado, quantidade de sangue colhido, temperatura de conservação, parâmetros bioquímicos e, inclusive, da freqüência de homogenização durante o armazenamento (WILLER; RIEDESEL, 1985; AUTHEMENT et al. 1986; LOPES, 1995; HÖGMAN et al. 2002). Segundo Patterson et al. (2011), reações transfusionais de caráter agudo podem ser ocasionadas por bolsas de sangue mantidas em temperaturas inadequadas por períodos superiores a um mês.

Tendo em vista as dificuldades em manter estoques em um banco de sangue veterinário, torna-se de fundamental importância a padronização da coleta, além da separação do plasma para que as hemácias possam ser preservadas por um período maior de tempo, pois este procedimento de separação diminui os riscos de uma contaminação e proliferação bacteriana, além de maximizar a utilização dos componentes sanguíneos, sem comprometer a manutenção de seus parâmetros bioquímicos. Além disso, em medicina veterinária, poucos estudos têm sido direcionados à conservação do sangue canino para transfusão (RIBEIRO FILHO et al., 1994; COSTA JUNIOR et al., 2008).

O presente trabalho teve como principais objetivos avaliar e comparar as alterações bioquímicas e hemogasométricas do sangue total canino armazenado em bolsas contendo CPDA-1 durante 30 dias.

\section{MATERIAL E MÉTODOS}

Foram utilizados oito cães adultos hígidos pesando aproximadamente $20 \mathrm{Kg}$, provenientes do canil da Universidade do Oeste Paulista. O estado de higidez dos animais foi atestado por exame clínico, hemograma, dosagem das proteínas plasmáticas totais, exames parasitológicos e pesquisas de hemoparasitas.

O sangue foi colhido por punção da veia jugular utilizando métodos assépticos e transferidos para bolsas de sangue estéreis (Fresenius Hemocare Brasil LTDA) e de uso único para evitar a contaminação bacteriana. No local da venopunção, uma tricotomia foi realizada, para em seguida ser feita uma assepsia com álcool isopropílico a $70 \%$, seguida de tintura de iodo a $2 \%$.

Um total de $3 \mathrm{~mL}$ foi retirado das bolsas de sangue logo após a coleta no dia (D0) e nos dias sete (D7), 14 (D14), 21 (D21) e 30 (D30). Durante todo o período, as bolsas permaneceram sob refrigeração $\left(-2\right.$ a $\left.8^{0} \mathrm{C}\right)$. As alíquotas foram submetidas aos exames de dosagem de glicose plasmática por espectrofotometria colorimétrica (Labtest), sódio e potássio por íons seletivos (Hemogasômetro Cobas-Roche), proteína plasmática total por refratometria (refratômetro 
Atago) e mensuração da $\mathrm{pO}_{2}, \mathrm{pCO}_{2}$, bicarbonato e $\mathrm{pH}$ sanguíneos por aparelho de hemogasometria (Hemogasômetro CobasRoche).

A análise estatística foi realizada utilizando 0 programa GraphPad InStat. Posteriormente, os dados que passaram pelas premissas desta análise de variância foram submetidos ao teste de Tukey, com grau de significância de $5 \%$, que avaliou o comportamento das variáveis no decorrer do tempo (PAGANO; GAUVREAU, 2004).

\section{RESULTADOS E DISCUSSÃO}

Os resultados obtidos referentes às análises bioquímicas e hemogasométricas das bolsas de sangue estão descritas na tabela abaixo.

Tabela 1. Valores médios de glicose, sódio, potássio, bicarbonato, proteína plasmática, $\mathrm{pCO}_{2}, \mathrm{pO}_{2} \mathrm{e} \mathrm{pH}_{\text {de }}$ bolsas de sangue de cães doadores do Hospital Veterinário da Unoeste mantidos durante 30 dias sob refrigeração.

\begin{tabular}{lcccccc}
\hline Variáveis/Dias & $\mathrm{D} 0$ & $\mathrm{D} 7$ & $\mathrm{D} 14$ & $\mathrm{D} 21$ & $\mathrm{D} 30$ & Valores normais \\
\hline Glicose $(\mathrm{mg} / \mathrm{dL})$ & $424,00^{\mathrm{a}}$ & $354,38^{\mathrm{a}}$ & $211,25^{\mathrm{b}}$ & $134,13^{\mathrm{b}}$ & $154,63^{\mathrm{b}}$ & $62,0-108,0$ \\
Sódio $(\mathrm{mEq} / \mathrm{L})$ & $148,81^{\mathrm{a}}$ & $154,55^{\mathrm{a}}$ & $157,24^{\mathrm{a}}$ & $158,61^{\mathrm{a}}$ & $158,26^{\mathrm{a}}$ & $141,0-153,0$ \\
Potássio $(\mathrm{mEq} / \mathrm{L})$ & $2,69^{\mathrm{a}}$ & $3,76^{\mathrm{b}}$ & $4,28^{\mathrm{c}}$ & $4,81^{\mathrm{d}}$ & $5,11^{\mathrm{d}}$ & $3,7-5,8$ \\
Bicarbonato $(\mathrm{mMol} / \mathrm{L})$ & $17,04^{\mathrm{a}}$ & $9,84^{\mathrm{b}}$ & $5,16^{\mathrm{cd}}$ & $3,34^{\mathrm{c}}$ & $1,99^{\mathrm{d}}$ & $17,0-24,0$ \\
$\mathrm{PPT}(\mathrm{g} / \mathrm{dL})$ & $7,03^{\mathrm{a}}$ & $7,13^{\mathrm{a}}$ & $7,20^{\mathrm{a}}$ & $8,78^{\mathrm{b}}$ & $10,23^{\mathrm{b}}$ & $6,0-8,0$ \\
$\mathrm{pCO}_{2}(\mathrm{mmHg})$ & $64,36^{\mathrm{a}}$ & $122,19^{\mathrm{b}}$ & $113,49^{\mathrm{b}}$ & $94,29^{\mathrm{b}}$ & $53,80^{\mathrm{a}}$ & $35,0-45,0$ \\
$\mathrm{pO}_{2}(\mathrm{mmHg})$ & $79,84^{\mathrm{a}}$ & $105,19^{\mathrm{a}}$ & $65,20^{\mathrm{ab}}$ & $89,50^{\mathrm{ac}}$ & $134,24^{\mathrm{ad}}$ & $85,0-95,0$ \\
$\mathrm{pH}^{\mathrm{a} H}$ & $7,04^{\mathrm{a}}$ & $6,51^{\mathrm{b}}$ & $6,25^{\mathrm{c}}$ & $6,15^{\mathrm{cd}}$ & $6,18^{\mathrm{c}}$ & $7,31-7,42$ \\
\hline
\end{tabular}

Valores seguidos de letras distintas indicam significância estatística ao nível de 5\%.

\section{A concentração plasmática da glicose} sofreu alteração ao longo dos tempos experimentais $(p<0,05)$, chegando a $50 \%$ de seu valor no $14^{0}$ dia. O elevado valor da glicose plasmática no primeiro dia foi ocasionado pela presença de glicose na solução preservadora (CPDA-1) (RIBEIRO FILHO et al., 1994). Provavelmente, os altos valores iniciais de glicose observado no plasma fizeram com que não houvesse decréscimo significativo nos seus valores, apesar do consumo deste carboidrato pelas hemácias.

O sódio plasmático, embora apresentasse um comportamento peculiar, estatisticamente não demonstrou diferenças na comparação entre momentos. Como o sódio é um eletrólito tipicamente extracelular, pode-se sugerir que não houve perda de água para o exterior das bolsas. Estes resultados corroboram os achados de Hess e Greenwalt (2002), quando afirmaram que o plástico das bolsas permite a saída apenas do $\mathrm{CO}_{2}$.

$\mathrm{Na}$ análise do potássio plasmático, foi observado um aumento significativo durante todo o período estudado. Notou-se que os níveis do potássio plasmático não excederam a 5,1 mEq/L. Este achado contraria os de Kurup et al. (2003), quando, em estudo com sangue humano conservado em bolsas CPD/SAG-M por 28 dias de refrigeração, encontraram médias de $6,1 \mathrm{mEq} / \mathrm{L}$ no último dia de armazenagem. Entretanto, este resultado confirma as observações de Kerr (2003) e de Korte e Verhoeven (2004), quando afirmaram que, em cães, os níveis intracelulares do potássio são menores, quando comparados a outras espécies, inclusive o homem.

A diminuição da capacidade de manter a concentração intracelular de potássio e extracelular de sódio é devido à diminuição do 
ATP na solução conservadora (HASHIMOTO, 1997; COSTA JUNIOR, 2008). Porém, baixos níveis de $\mathrm{pH}$ influenciam diretamente neste equilíbrio, promovendo uma migração do potássio para o meio extracelular (BUSH, 2004; MEYER; HARVEY, 2004). O aumento de potássio também é indicativo de hemólise, resultado este encontrado neste experimento ao final dos 30 dias.

No estudo do bicarbonato plasmático, foi notado um declínio no decorrer do tempo. Segundo Luna (2002), o bicarbonato é uma base fraca, responsável por mais de $50 \%$ da capacidade tamponante do meio extracelular. Por isso, esta redução nos valores sangüíneos pode ser explicada por um consumo deste íon no controle da acidez, reduzindo os seus níveis na mesma proporção em que há a produção de ácidos metabólicos no interior das bolsas. Este declínio do bicarbonato também foi encontrado por Ribeiro Filho et al. (1994), em estudo com sangue bovino conservado em bolsas CPDA-1.

Os níveis da proteína plasmática se mantiveram estáveis até 14 dias de armazenamento. A partir deste período, houve um aumento desta variável $(p<0,05)$, o que pode indicar uma maior perda de componentes intracelulares (LOPES, 1995).

No estudo da $\mathrm{pCO}_{2}$, foi observado um aumento significativo dos níveis na primeira semana reduzindo após este período. Esta variação também foi observada por Ribeiro Filho et al. (1994), que estudaram o sangue bovino em bolsas CPDA-1. Segundo Högman et al. (2002), altos níveis da $\mathrm{pCO}_{2}$ expõem o 2,3 DPG (2,3 difosfoglicerato), que é uma molécula presente no interior das hemácias e que se liga à subunidade $\beta$ da hemoglobina. O 2,3DPG é responsável pela liberação do oxigênio $\left(\mathrm{O}_{2}\right)$ para os tecidos (SCOTT et al., 2005). Desse modo, quanto menor os níveis de DPG, maior será a afinidade da hemoglobina pelo $\mathrm{O}_{2}$, dificultando a liberação deste elemento para os tecidos, provavelmente por competir por seu sítio de ligação na hemoglobina. $\mathrm{O}$ aumento da $\mathrm{pCO}_{2}$ no sangue armazenado também se deve à neutralização do ácido láctico produzido pelo metabolismo celular, resultando na produção de $\mathrm{CO}_{2}$ (RIBEIRO FILHO et al., 1994).

Houve uma oscilação dos valores de $\mathrm{pO}_{2}$, com um aumento aos 30 dias de estocagem. Este dado corrobora os resultados encontrados por Ribeiro Filho et al. (1994), os quais, em estudos com sangue bovino em bolsas CPDA-1, relataram que o plástico das bolsas é permeável ao $\mathrm{O}_{2}$. Este fato pode explicar o aumento dos níveis da pO2 no sangue. Entretanto, contraria as afirmações de Högman et al. (2002), quando relataram que o plástico é permeável apenas ao $\mathrm{CO}_{2}$, sendo pobremente transpassado por outros gases.

Ao longo dos momentos de análise, observou-se a queda gradativa do $\mathrm{pH}$ com diferença $(p<0,05)$. Considerando que o sangue canino em condições normais possui pH em torno de 7,3, ocorreu a diminuição dessa variável logo no primeiro dia, decorrente da acidez natural da solução preservativa (CPDA-1) e posteriormente em decorrência da produção de metabólitos ácidos pela hemácias armazenadas (RIBEIRO FILHO et al., 1994; COSTA JUNIOR, 2008). Valores de $\mathrm{pH}$ inferiores a sete favorecem a degradação do DPG, contribuindo de forma significativa na deterioração da capacidade da hemácia em carrear oxigênio (HESS; GREENWALT, 2002; KURUP et al., 2003). Patterson et al. (2011) verificaram que a hemólise pode alterar as características sanguíneas e ocasionar reações adversas em cães, quando as bolsas de sangue são armazenadas em temperaturas inadequadas por períodos superiores a um mês.

Pode-se concluir que as bolsas de sangue, quando armazenadas entre -2 e $8^{0} \mathrm{C}$, 
devem ser utilizadas no período máximo de quinze dias para preservação de seus componentes.

\section{COMITÊ DE ÉTICA}

O presente experimento foi aprovado pelo Comitê de Ética em Pesquisa da Instituição de origem, protocolada sob o número 048/08.

\section{REFERÊNCIAS}

AUTHEMENT, J.M.; WOLFSHEIMER, K.J.; CATCHINGS, S. Canine blood component therapy: product preparation, storage and administration. Journal of American Animal Hospital Association, Denver, v. 23, p.483-493, 1986.

BUSH, B. M. Interpretação de Resultados Laboratoriais para Clínicos de Pequenos Animais. São Paulo: Roca, 2004.

COSTA JUNIOR, J.; RIBEIRO FILHO, J.D.; FAVARATO, E.S.; MATA, L.C. Parâmetros bioquímicos e hemogasométricos do sangue total canino armazenado em bolsas plásticas contendo CPDA-1 e CPD/SAG-M. Ciência Rural, Santa Maria, v.38, p.378-383,2008.

http://dx.doi.org/10.1590/S0103-

84782008000200013.

HASHIMOTO, M. C. T. Estudo da preservação de sangue em diferentes bolsas de coleta com di-octil-ftalato e anticoagulante citrato-fosfatodextrose-adenina. 1997. Dissertação (Mestrado em Farmacologia) - Faculdade de Ciências Médicas, Universidade Estadual de Campinas, Campinas.

HESS, J. R.; GREENWALT, T. J. Storage of blood cells: new approaches. Transfusion Medicine Review, Orlando, v. 16, n. 4, p. 283295, 2002.

HÖGMAN, C.F.; KNUSTON, F.; LÖÖF, H.; PAYRAT, J.M. Improved maintenance of 2,3 DPG and ATP in RBC's stored in a modified additive solution. Transfusion, Philadelphia, v.42, p.824829, 2002.

HOSGOOD, G. Blood transfusion: a historical review. Journal of American Veterinary Medical Association, Canada, v. 197, n. 8, p. 998-1000,1990.

JAIN, N. C. Essentials of Veterinary

Hematology. Philadelphia : Lea \& Febiger, 1993.

KERR, M. G. Exames laboratoriais em medicina veterinária: bioquímica clínica e hematologia. 2.ed. São Paulo: Roca, 2003.

KORTE, D.; VERHOEVEN, A. J. Quality determinants of erythrocyte destined for transfusion. Cellular and Molecular Biology, France, v. 50, n. 2, p. 187-195, 2004.

KRISTENSEN, A. T.; FELDMAN, B. F. Bancos de sangue e medicina transfusional. In: ETTINGER, E. J.; FELDMAN, E. C. Tratado de Medicina Interna Veterinária. 4.ed. Manole: Barueri, 1997. v. 1, p. 497-517. KURUP, P.A.; ARUN, P.; GAYATHRI, N.S.; DHANYA, C.R.; INDU, A.R. Modified formulation of CPDA for storage of whole, and of SAMG for storage or red blood cells to maintain the concentration or 2,3-diphosphoglycerate. Vox Sanguinis, England, v.85, p.253-261, 2003.

LOPES, R. S. Alterações hematológicas e bioquímicas em sangue total de eqüinos, conservado para transfusão em bolsas plásticas com ACD-F. Revista Universidade Rural: Ciência da vida, Rio de Janeiro, v. 17, p. 91-94, 1995.

LUNA, S. P. L. Equilíbrio ácido-básico. In: FANTONI, D. T.; CORTOPASSI, S. R. G. (Ed.). Anestesia em cães e gatos. São Paulo: Roca, 2002. p. 120-129. 
MEYER, J. D., HARVEY, J. W. Veterinary

laboratory medicine. Philadelphia: Saunders

Company, 2004.

NUSBACHER, J. Blood transfusion in mononuclear cell transplantation. Transfusion,

Philadelphia, v. 34, p. 1002-1004, 1994.

PAGANO, M.; GAUVREAU, K. Princípios de bioestatística. São Paulo: Pioneira Thomson Learning, 2004.

PATTERSON, J.; ROUSSEAU, A.; KESSLER, N.S.; GIGER, U. In vitro lysis and acute transfusion reactions with hemolysis caused by inappropriate storage of canine red blood cell products. Journal of Veterinary Internal Medicine, v.25, n.4, p.927-933, 2011. http://dx.doi.org/ 10.1111/j.19391676.2011.0737.x.

RIBEIRO FILHO, J.D.; ALMEIDA, C.T.;

GOMÇALVES, R.C.; KOHAYAGAWA, A.; CURY, P. Alterações hemogasométricas de sangue bovino durante a conservação em frascos de vidro com ACD e bolsas plásticas com CPDA-1, por 35 dias. Veterinary Zootecnic, v.6, p.77-84, 1994.

ROZANSKI, E.; LAFORCADE, A. M. Transfusion medicine in veterinary emergency and critical care medicine. Clinical Techniques in Small Animal Practice, Philadelphia, v. 19, n. 2, p. 83-87, 2004. SCOTT, K. L.; LECAK, J.; ACKER, J. P. Biopreservation of red blood cells: past, present, and future. Transfusion Medicine Reviews, Orlando, v. 19, n. 2, p. 127-142, 2005.

WILLER, R. L.; RIEDESEL, D. H. Transfusion therapy and blood banking in the dog and cat. lowa: State University Veterinary, 1985. v. 47, p. 102-109. 